\title{
Assessment of Genotype × Trait × Environment interactions of silage maize genotypes through GGE Biplot
}

\author{
Mahmut Kaplan $^{1 *}$, Kagan Kokten², and Mevlut Akcura ${ }^{3}$
}

\section{INTRODUCTION}

In yield experiments conducted at different environments, assessment of Genotype $\times$ Environment interactions for investigated traits is a quite significant issue for both agronomists and breeders. GGE biplot analysis was employed in this study to assess the Genotype $\times$ Trait, Environment $\times$ Trait and Trait Association $\times$ Environment of five different traits (silage yield [SY], stem diameter [SD], green leaf weight ratio [GLWR], green stem weight ratio [GSWR], green corn cob ratio [GCCR] and plant height $[\mathrm{PH}]$ ) of 25 silage maize (Zea mays L.) genotypes grown in six environments. The biplot graphs created in this study to assess Genotype $\times$ Trait, Environment $\times$ Trait and Environment $\times$ Trait correlation interactions were able to explain respectively $86 \%, 92 \%$, and $83 \%$ of total variation of experiments. Current findings revealed that the genotype G18 (Safak), with the greatest silage yield in Genotype Trait biplot (GT biplot) also had the greatest SD; DIY14 (DIYARBAKIR-2014) with the greatest distance from the origin over Environment Trait (ET-biplot) graph was the most distinctive environment; SD with the greatest vector length was the most distinctive trait; DIY14 and DIY15 environments were the best environments for $\mathrm{PH}$, GSWR, SY and SD. It was concluded that GGE biplot method with different perspectives could reliably be used in assessment of silage characteristics of maize genotypes grown in different environments.

Key words: GGE biplot, multienvironment, plant trait, silage hybrid maize, yield, Zea mays.

${ }^{1}$ University of Erciyes, Faculty of Agriculture, 38220 Kayseri, Turkey. "Corresponding author (mahmutkaplan5@hotmail.com).

${ }^{2}$ University of Bingol, Faculty of Agriculture, 12400 Bingol, Turkey. ${ }^{3}$ University of Canakkale Onsekiz Mart, Faculty of Agriculture, 17100 Canakkale, Turkey.

Received: 14 February 2017.

Accepted: 20 June 2017.

doi:10.4067/S0718-58392017000300212
Maize (Zea mays L.) is used in animal nutrition either as green fodder or silage. It is one of the most important juicy roughage (Erdal et al., 2009). High unit-area yield and adaptation capacity, availability for silage, high energy content, sufficient sugar content to preserve for long durations without any additives, the greatest digestible nutrient content, high nutritional values, long-duration storage and fresh consumption in winters, make maize as the most preferred plant for livestock feeding (Kusvuran et al., 2015)

Although researchers investigated several traits in different environments, they usually experienced problems in assessments of these traits. The problem gets complicated in selection studies especially when there is a negative interaction between the primary trait of the experiments and the other traits (De Leon et al., 2016). GGE biplot method is considered as the best method for reliable assessments in multi-environment experiments (Rahmatollah et al., 2013; Yan, 2014). The method was developed by Yan (2014) and it uses different types of biplot graphs created through adding Genotype $\times$ Environment interaction effect onto genotype main effects for the target trait.

GGE biplot method allows the user to assess entire twoway data (Dehghani et al., 2012). Assessments are usually performed over PC1 and PC2 axes calculated from the data of rows and columns from a two dimensional array produced by the combination of genotypes and environments in multipleenvironment datasets (Akcura and Kokten, 2016). Different uses of the method were explained in detail by Yan (2014). GGE biplot method is commonly used for visual assessment of Genotype $\times$ Environment interaction for grain yield of different plants in multi-environment experiments (Roozeboom et al., 2008; Dehghani et al., 2009; Mohammadi et al., 2009; Yan et al., 2010; Akcura et al., 2011; Mohammadi and Amri, 2016).

The method is also used for visual assessments of correlations among investigated traits through Genotype $\times$ Trait biplot graph (Yan and Frégeau-Reid, 2008; Akcura, 2009; Akcura and Kokten, 2017). GGE biplot was used in assessment of different characteristics of genotypes in several field crops. GGE biplot was also employed in variety evaluation of wheat (Akcura, 2011; Gholizadeh and Dehghani, 2016), oat (Yan et al., 2010), common bean (Villegas et al., 2016) and oat (Yan et al., 2007; Yan and Frégeau-Reid, 2008).

In multi-environment experiments, beside the primary trait, significance of other characteristics is also identified. However, 
GGE biplot graphs should accurately and efficiently be interpreted along with the objectives of the study. In silage maize, beside silage yield, the other plant characteristics may also vary with environmental conditions. The plant characteristics to be used in variety selection in maize to be cultivated in different environments of target region should be determined before to design a study on maize cultivars. However, there are not studies in literature assessing silage yield and yield characteristics of several maize genotypes under different environments. In present study, Genotype $\times$ Trait (GT), Environment $\times$ Trait $(E T)$ and Trait Association $\times$ Environment (TAE) of different plant characteristics of 25 silage maize genotypes grown in six environments were assessed through GGE biplot analysis.

\section{MATERIALS AND METHODS}

Silage maize genotypes used in this study and their supplier organizations and institutions are provided in Table 1.

Experiments were conducted in Bismil (37 $50^{\prime} \mathrm{N}, 40^{\circ} 39^{\prime}$ E; $535 \mathrm{~m}$ a.s.1.), Diyarbakir Province, Elazig Province (3840’ N, 39¹3' E; $1070 \mathrm{~m}$ a.s.1.), and Bingol Province (385' N, 40²9' E; 1153 m a.s.1.), Turkey, during the growing seasons of 2014 and 2015 in randomized blocks design with three replicates. Experimental plots were $5 \mathrm{~m}$ long. Each plot had 4 rows with $70 \mathrm{~cm}$ row spacing and 15 $\mathrm{cm}$ on-row plant spacing. Sowing was performed as to have 33 seeds per row. Before sowing, $80 \mathrm{~kg} \mathrm{~N}, 80 \mathrm{~kg} \mathrm{P}\left(\mathrm{P}_{2} \mathrm{O}_{5}\right)$ and $80 \mathrm{~kg} \mathrm{~K}\left(\mathrm{~K}_{2} \mathrm{O}\right)$ fertilizers were supplied per hectare. When the plants reached 50-60 cm heights, dressing fertilizer was applied with hoeing and at tassel formation period as

Table 1. Silage maize genotypes and supplier organizations.

\begin{tabular}{rll}
\hline Nr & \multicolumn{1}{c}{ Genotype } & Supplier organization and institution \\
\hline G1 & 31 41 & Pioneer Seed Co. \\
G2 & $30 B 74$ & Pioneer Seed Co. \\
G3 & 31 Y3 & Pioneer Seed Co. \\
G4 & 31 A34 & Pioneer Seed Co. \\
G5 & $12-219$ & Panam France Seed Company \\
G6 & $12-218$ & Panam France Seed Company \\
G7 & 12-231HO & Panam France Seed Company \\
G8 & DKC 955 & Monsanto Company \\
G9 & DKC 6903 & Monsanto Company \\
G10 & DKC 6589 & Monsanto Company \\
G11 & DKC 7211 & Monsanto Company \\
G12 & DKC 6590 & Monsanto Company \\
G13 & R.U 4 H.D & Pioneer Seed Co. \\
G14 & DIAN & Panam France Seed Company \\
G15 & MARVIN & Panam France Seed Company \\
G16 & ELDORA & Panam France Seed Company \\
G17 & WAYNE & Italy Venturoli \\
G18 & SAFAK & Eastern Mediterranean Agricultural Research Institute \\
G19 & BATEM EFE & Eastern Mediterranean Agricultural Research Institute \\
G20 & TUONO & BetaAgriculture and Trade Co. \\
G21 & BURAK & Eastem Mediterranean Agricultural Research Institute \\
G22 & SEME KUKURUZA877 & Serbia Zemun Polje \\
G23 & SEME KUKURUZA873 & Serbia Zemun Polje \\
G24 & ADV 2898 & Limagrain Seed Breeding and Production Co. \\
G25 & TRUVA & Limagrain Seed Breeding and Production Co. \\
\hline & &
\end{tabular}

to have a total of $150 \mathrm{~kg} \mathrm{~N} \mathrm{ha}^{-1}$. Throughout the growing season, two hoeing and one earthing were performed.

Climate parameters and soil characteristics of experimental sites are provided in Table 2. In all three provinces, precipitations during the growing season were higher in the first year than in the second year. Experimental sites have loamy soil texture with slightly alkaline structure in Diyarbakir and Elazig provinces (respectively with a $\mathrm{pH}$ of 7.73 and 7.78) and slightly acidic structure in Bingol province ( $\mathrm{pH}$ 6.37). The lime content was medium in Diyarbakir and Elazig and low in Bingol province.

Data collection and analysis. All hybrid maize genotypes were manually harvested at milk-dough stage (about 30\% DM). Middle two rows were harvested manually and the side rows were omitted as to consider the side effect. Plants were harvested at milk-dough stage and morphological observations were performed just before the harvest. Plant samples were weighed and silage yields were determined in $\mathrm{t} \mathrm{ha}^{-1}$. Plant heights were measured over randomly selected 10 plants from each plot as the height from the soil surface to top tassel. Stem diameter was measured over the first node from the soil surface. Diameters were measured from randomly selected 10 plants between the first and second node from the soil surface and average value was expressed in $\mathrm{mm}$. Randomly selected five plants from each plot were separated into cob, stem, and leaves. Each part was weighed and green corn cob ratio, green stem weight ratio and green leaf weight ratio was determined.

The data obtained from all environments were initially subjected to variance analysis and LSD values were determined for significant traits. Then coefficient of correlation between traits were calculated with SAS software for each environment (SAS Institute, 1999).

In this study, four biplot graphs were created with different data matrix of the environments and genotypes by using GGE biplot software (Yan, 2014). These graphs were the one obtained from the data matrix including mean values of all traits of genotypes in all environments (Figure 1 ), one obtained from the matrix including the traits of genotype 18 with the greatest silage yield (Figure 2), the one obtained from the matrix including mean values of all traits in all environments (Figure 3 ) and the one obtained from the correlation matrix including means of investigated traits in every environment (Figure 4).

\section{RESULTS AND DISCUSSION}

In present study, 25 hybrid silage maize cultivars registered in Turkey were used. Average values for investigated traits in different environments are provided in Table 3.

Plant heights of different genotypes varied between $225.0 \mathrm{~cm}(\mathrm{G} 15)$ and $299.0 \mathrm{~cm}(\mathrm{G} 2)$, stem diameters varied between $21.3 \mathrm{~mm}(\mathrm{G} 14)$ and $26.2 \mathrm{~mm}$ (G18), green stem weight ratios varied between $35.1 \%(\mathrm{G} 14)$ and $52.2 \%(\mathrm{G} 21)$, green corn cob ratios varied between $29.1 \%$ (G2) and $47.1 \%$ (G14) and green leaf weight ratios varied between $16.0 \%$ (G19) and $21.0 \%$ (G2). Total silage/green herbage yield is 
Table 2. Climate parameters, soil characteristics and crop data for experimental sites and seasons.

\begin{tabular}{|c|c|c|c|c|c|c|c|c|}
\hline Code & Environments & Seasons & Altitude & $\begin{array}{c}\text { Annual } \\
\text { precipitation }\end{array}$ & Irrigation $^{1}$ & Soil & Sowing date & Harvest date \\
\hline & & & m a.s.l. & $\mathrm{mm}$ & & & & \\
\hline DIY14 & Diyarbakir & 2014 & 535 & 110.7 & $100 \times 4$ & Loamy, medium lime, pH 7.73 & 8 April & 21 July \\
\hline EL14 & Elazig & 2014 & 1070 & 121.5 & $100 \times 4$ & Loamy, medium lime, $\mathrm{pH} 7.78$ & 12 April & 8 August \\
\hline BIN14 & Bingol & 2014 & 1153 & 135.8 & $100 \times 4$ & Loamy, low lime, pH 6.37 & 5 May & 29 August \\
\hline DIY15 & Diyarbakir & 2015 & 535 & 67.2 & $100 \times 4$ & Loamy, medium lime, $\mathrm{pH} 7.73$ & 21 April & 1 August \\
\hline EL15 & Elazig & 2015 & 1070 & 64.8 & $100 \times 4$ & Loamy, medium lime, $\mathrm{pH} 7.78$ & 18 April & 15 August \\
\hline BIN15 & Bingol & 2015 & 1153 & 96.6 & $100 \times 4$ & Loamy, low lime, pH 6.37 & 4 April & 27 August \\
\hline
\end{tabular}

the most significant trait in silage maize culture. Total silage yields of the genotypes varied between $67.6 \mathrm{t} \mathrm{ha}^{-1}$ (G14) and $108.8 \mathrm{tha}^{-1}$ (G18). Environmental averages for six plant characteristics are provided in Table 4 . The average silage yields of experimental environments varied between 59.9 and $104 \mathrm{t} \mathrm{ha}^{-1}$ with the greatest silage yield in DIY14 and the second greatest yield $\left(97.4 \mathrm{t} \mathrm{ha}^{-1}\right)$ in DIY15 environments.

While the greatest green leaf weight ratio (GLWR) was observed in BIN14 environment with $19.49 \%$, the lowest value was observed in DIY14 environment with $16.05 \%$. The lowest green corn cobs ratio was obtained from DIY14 environment with $35.99 \%$ and the greatest value was obtained from BIN15 environment with $43.84 \%$. Green stem weight ratios of the environments varied between $38.01 \%$ (BIN15) and $47.97 \%$ (DIY14), stem diameters

Figure 1. Genotype $\times$ Trait biplot for investigated traits of maize genotypes.

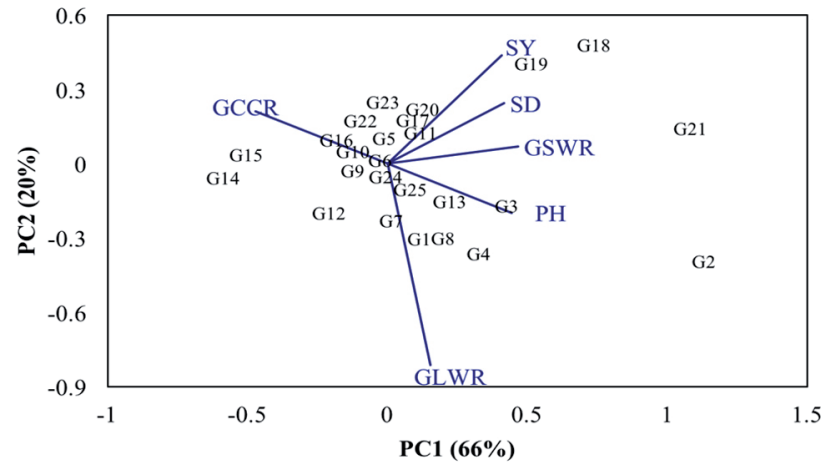

PH: Plant height; SD: stem diameter; GSWR: green stem weight ratio; GCCR: green corn cob ratio; GLWR: green leaf weight ratio; SY: silage yield.

Figure 2. Biplot for the correlations between the traits of genotype Safak (G18) with the greatest silage yield.

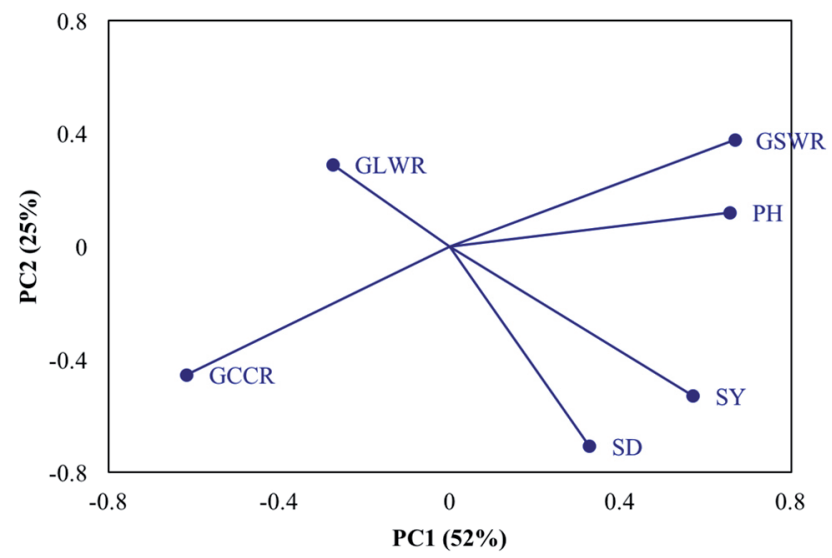

PH: Plant height; SD: stem diameter; GSWR: green stem weight ratio; GCCR: green corn cob ratio; GLWR: green leaf weight ratio; SY: silage yield. varied between $21.09 \mathrm{~mm}$ (BIN14) and $25.35 \mathrm{~mm}$ (DIY14) and plant heights varied between $213.57 \mathrm{~cm}$ (BIN15) and 302.37 (DIY14) (Table 4).

Genotype $\times$ trait interaction (GTI) biplot graph was created for visual assessment of investigated traits over the environments (Figure 1). The graph was able to explain $86 \%$ of total variation. Positively correlated traits and the best genotypes for each trait were placed close to each other over the graph. The graph about the correlations between the traits of the genotype Safak (G18) with the greatest silage yield is presented in Figure 2.

The environment-trait biplot (ETI biplot) graph for visual assessment of variations in traits based on environments is presented in Figure 3. The graph was created with PC1 and $\mathrm{PC} 2$ axes and the graph was able to explain $92 \%$ of total variation. The DIY14 environment was placed at the furthest distance from the origin and it was the most distinctive environment. The SD trait had the greatest vector length and thus became the trait with the highest variation among genotypes.

The correlations between traits calculated for each environment are provided in Table 5. The greatest correlation coefficient $(r=-0.95)$ was observed in DIY15 and EL15 environments between GSWR and GCCR and the lowest correlation coefficient $(r=-0.02)$ was identified in DIY15 environment between GSWR vs. GLWR.

As it was in assessment of Environment $\times$ Trait interaction, Trait Association $\times$ Environment (TAE) biplot were drawn by using the correlation coefficients separately calculated between the traits in each environment (Figure 4). Two-way

Figure 3. The trait vector form of the environment-by-trait biplot based on the environment-by-trait data across cultivars.

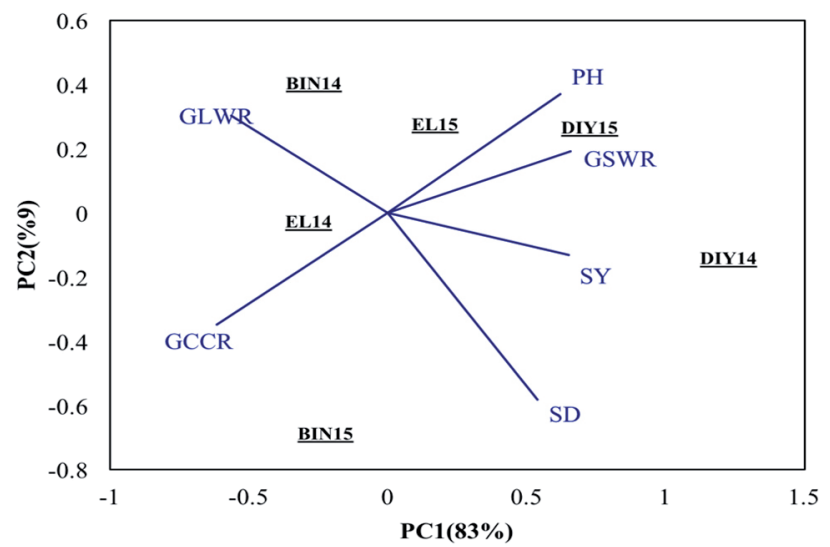

PH: Plant height; SD: stem diameter; GSWR: green stem weight ratio; GCCR: green corn cob ratio; GLWR: green leaf weight ratio; SY: silage yield. 
Figure 4. The trait association-by-environment (ABE) biplot displaying the association-by-environment two-way table of correlations in Table $5^{\dagger}$.

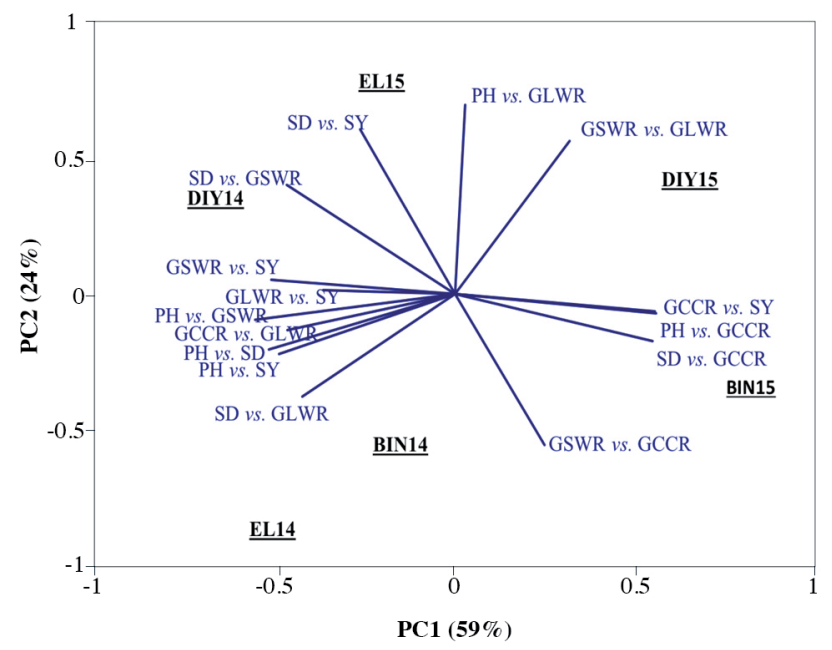

Vector length of each associations are $\mathrm{PH} v$ s. $\mathrm{SD}=0.90 ; \mathrm{PH}$ vs. GSWR $=1.00$; $\mathrm{PH} v s . \mathrm{GCCR}=1.50 ; \mathrm{PH} v s . \mathrm{GLWR}=1.20 ; \mathrm{PH} v s . \mathrm{SY}=0.90 ; \mathrm{SD} v s . \mathrm{GSWR}$ $=1.00 ; \mathrm{SD} v s . \mathrm{GCCR}=1.40 ; \mathrm{SD} v s . \mathrm{GLWR}=1.00 ; \mathrm{SD} v s . \mathrm{SY}=1.10 ; \mathrm{GSWR}$ vs. GCCR $=1.30 ;$ GSWR vs. GLWR $=1.30 ;$ GSWR vs. $\mathrm{SY}=0.80 ;$ GCCR $v s$. GLWR $=0.80 ;$ GCCR $v s . \mathrm{SY}=1.40 ;$ GLWR $v s . \mathrm{SY}=0.50$

PH: Plant height; SD: stem diameter; GSWR: green stem weight ratio; GCCR: green corn cob ratio; GLWR: green leaf weight ratio; SY: silage yield. VL: Vector length of each association in Figure 4

correlations were placed over the graph based on positive or negative, small and large nature of correlation coefficients. The ABE biplot was first reported in Yan and Tinker (2005) and Yan et al. (2007). The vector length of a trait association in the TAE biplot indicates the strength of the association.
The graphs created to assess two-way interactions (Figures 1, 3 and 4) were able to explain respectively $86 \%$, $92 \%$ and $83 \%$ of total variation. Such explanation rates were quite higher than the values reported in previous studies. For instance, Akcura et al. (2011) reported an explanation rate of $76.14 \%$ in wheat, Villegas et al. (2016) reported more than $75 \%$ in common bean, Meng et al. (2016) reported $71.5 \%$ in barley.

In present study, all interactions in multi-environment experiments were assessed through GGE biplot graphs. In the first graph, GTI biplot graph (Figure 1) was created by using trait averages of genotypes in different Environments and Genotype $\times$ Trait interactions were assessed over this graph. With this graph, traits had higher vector length of each genotype in each environment and the traits with either positive or negative correlations were identified (Yan, 2014). While the genotype G18 had the greatest silage yield, G21 was prominent with SD and GSWR, G2 with plant height, G4 with GLWR and genotype 15 with GCCR. As it was in GGE biplot graphs, the angle between positively correlated traits narrowed and they were placed close to each other over the graph (Yan, 2014). The genotypes with high silage yields had also higher stem diameters.

The averages for each trait in different environments are provided in Table 4. Which trait is well in which environment(s) can be seen in this table. However, the Environment $\times$ Trait biplot created by using the table data allows the user better assessment of data. As it can be seen from the graph (Figure 3), there were significant positive correlations of plant height with green stem weight ratio and silage yield; silage yield was positively correlated with green

Table 3. Average values of traits of 25 genotypes for different environments.

\begin{tabular}{|c|c|c|c|c|c|c|c|}
\hline Genotypes & Cultivars & $\mathrm{PH}$ & SD & GSWR & GCCR & GLWR & SY \\
\hline & & $\mathrm{cm}$ & $\mathrm{mm}$ & 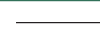 & $-\%$ & $\bar{L}$ & $\mathrm{tha}^{-1}$ \\
\hline G1 & $31 \mathrm{P} 41$ & 254.1 & 23.8 & 39.4 & 40.3 & 20.3 & 76.3 \\
\hline $\mathrm{G} 2$ & $30 B 74$ & 299.0 & 24.0 & 49.8 & 29.1 & 21.0 & 97.4 \\
\hline G3 & $31 Y 43$ & 271.0 & 23.7 & 43.8 & 37.1 & 19.1 & 82.2 \\
\hline G4 & 31A34 & 265.0 & 23.7 & 42.2 & 37.4 & 20.5 & 77.3 \\
\hline G5 & $12-219$ & 259.9 & 22.7 & 41.1 & 41.9 & 17.0 & 79.8 \\
\hline G6 & $12-218$ & 254.9 & 22.6 & 40.6 & 41.8 & 17.6 & 77.4 \\
\hline G7 & $12-231 \mathrm{HO}$ & 252.6 & 22.5 & 41.2 & 39.7 & 19.0 & 72.2 \\
\hline G8 & DKC 955 & 265.9 & 22.7 & 40.9 & 39.2 & 19.9 & 80.3 \\
\hline G9 & DKC 6903 & 249.7 & 21.8 & 41.8 & 41.0 & 17.2 & 70.3 \\
\hline G10 & DKC 6589 & 239.2 & 22.7 & 40.4 & 41.9 & 17.6 & 77.2 \\
\hline G11 & DKC 7211 & 257.2 & 22.4 & 43.0 & 40.2 & 16.8 & 82.2 \\
\hline G12 & DKC 6590 & 248.1 & 21.6 & 38.1 & 43.0 & 18.9 & 74.4 \\
\hline G13 & R.U 4 H.D & 252.1 & 24.0 & 42.4 & 38.5 & 19.1 & 75.6 \\
\hline G14 & DIAN & 230.7 & 21.3 & 35.1 & 47.1 & 17.8 & 67.6 \\
\hline G15 & MARVIN & 225.0 & 21.6 & 37.2 & 45.5 & 17.3 & 69.3 \\
\hline G16 & ELDORA & 243.4 & 21.9 & 40.2 & 42.8 & 16.9 & 76.5 \\
\hline G17 & WAYNE & 251.1 & 24.2 & 40.0 & 42.7 & 17.4 & 83.6 \\
\hline G18 & SAFAK & 260.4 & 26.2 & 45.1 & 37.9 & 16.9 & 108.8 \\
\hline G19 & BATEM EFE & 267.1 & 24.1 & 45.5 & 38.5 & 16.0 & 98.3 \\
\hline G20 & TUONO & 264.5 & 23.7 & 39.6 & 43.5 & 16.9 & 87.3 \\
\hline G21 & BURAK & 271.6 & 25.7 & 52.2 & 29.8 & 18.0 & 97.5 \\
\hline $\mathrm{G} 22$ & SEME KUKURUZA 877 & 241.2 & 22.3 & 41.4 & 41.7 & 16.9 & 83.3 \\
\hline G23 & SEME KUKURUZA 873 & 250.4 & 22.6 & 41.3 & 42.3 & 16.4 & 82.2 \\
\hline G24 & ADV 2898 & 243.1 & 23.5 & 38.5 & 43.0 & 18.5 & 85.6 \\
\hline \multirow[t]{2}{*}{$\mathrm{G} 25$} & TRUVA & 255.6 & 22.7 & 42.5 & 39.4 & 18.1 & 72.6 \\
\hline & $\operatorname{LSD}(0.01)$ & 14.66 & 1.84 & 3.56 & 3.83 & 1.88 & 1.37 \\
\hline
\end{tabular}

PH: Plant height; SD: stem diameter; GSWR: green stem weight ratio; GCCR: green corn cob ratio; GLWR: green leaf weight ratio; SY: silage yield. 
Table 4. Average data of genotype traits for the different environments and seasons.

\begin{tabular}{lcrrrrr}
\hline Variable & PH & SD & GSWR & GCCR & GLWR & SY \\
\hline & $\mathrm{cm}$ & $\mathrm{mm}$ & & $\%$ & & t ha $^{-1}$ \\
\cline { 6 - 7 } BIN14 & 226.04 & 21.09 & 38.55 & 41.96 & 19.49 & 59.9 \\
BIN15 & 213.57 & 23.67 & 38.01 & 43.84 & 18.15 & 77.0 \\
DIY14 & 302.37 & 25.35 & 47.97 & 35.99 & 16.05 & 104.0 \\
DIY15 & 277.42 & 24.35 & 45.48 & 36.21 & 18.31 & 97.4 \\
EL14 & 237.82 & 22.60 & 38.85 & 42.32 & 18.84 & 66.6 \\
EL15 & 272.22 & 21.61 & 41.56 & 40.99 & 17.46 & 83.5 \\
LSD (0.01) & 7.2 & 0.89 & 1.74 & 1.88 & 0.92 & 0.67
\end{tabular}

PH: Plant height; SD: stem diameter; GSWR: green stem weight ratio; GCCR: green corn cob ratio; GLWR: green leaf weight ratio; SY: silage yield.

stem weight ratio and stem diameter; there were significant correlations between plant height and green corn cob ratio.

With the same graph, which trait is significant in which environment is also explained (Yan, 2014). The environments DIY14 and DIY15 were identified as the best environment for plant height, green stem weight ratio, silage yield and stem diameter (Figure 3). BIN15 environment was identified as the best environment for green corn cob ratio, and BIN14 environment was the best for green leaf weight ratio. Based on this information, Diyarbakir was identified as the best environment for silage maize culture of the region.

Among the genotypes, Safak (G18) had the greatest silage yield. It can be inferred from the graph explaining the correlations between the traits of this cultivar that silage yield was positively correlated with plant height, stem diameter and green stem weight ratio (Figure 2).

In multi-environment experiments with different traits, since experiments were assessed separately, researchers are sometimes not able to explain the relationships they wish to explain (Gholizadeh and Dehghani, 2016). In such experiments, rather than interpreting several correlation coefficients, ABE biplot (association by environment biplot) provide the best assessments. ABE biplot was recommended by Yan (2014). The ABE biplot is presented in Figure 4. There were not any remarkable differences in vector lengths of correlation coefficients. However, the vectors for GCCR vs. SY, PH vs. GCCR and SD vs. GCCR were relatively longer.

Among the experimental environments, in BIN15 environment, the greatest correlation coefficient was observed between SD vs. GCCR, this two-way correlation was also placed at close position over the graph. The correlation coefficient between SD vs. GSWR was positive and significant in all environments except BIN15. However, DIY14 and EL15 environments had the greatest correlation coefficients. SD vs. GSWR and these two environments were placed closer to each other over the graph.

The DIY14 environment should also be assessed in the same fashion. This environment had the greatest silage yield, plant height, green stem weight ratio and stem diameter. The correlation coefficients of this environment were also higher than the other environments. Such a case was quite remarkable over the graph. The environments with high silage yields have also the other traits at high rates. Besides silage yields of silage maize genotypes, cob, stem and leaf ratios were indicated as significant factors influencing the quality (Kaplan et al., 2016).

It was observed in this study that GGE biplot analysis was quite handy method for visual assessment of data matrices composed of two-way data (Yan, 2014). However, the method has not been widely used by the researchers, yet. Compared to conventional methods, GGT biplot method eases the interpretation of Genotype $\times$ Trait interaction through visualizing silage yield data and allows the users to separately assess each genotype and each trait (Yan et al., 2007).

In multi-environment experiments, conventional methods usually do not allow the assessment of entire traits or separate assessment of each trait (Yan, 2014). The environment-trait ET-biplot used in present study allowed together assessment of all traits related to silage yield. With this method, how each trait changes in each environment can be assessed (Yan, 2014). Environment-trait biplot graph allows researchers to select an environment and trait for the experiments.

Trait association-by-environment (ABE) biplot is used relatively less than the other biplots. In multi-environment

Table 5. Correlations between the traits in different environments $(n=75)$.

\begin{tabular}{|c|c|c|c|c|c|c|c|}
\hline Trait pairs & BIN14 & BIN15 & DIY 14 & DIY15 & EL14 & EL15 & $\mathrm{VL}$ \\
\hline $\mathrm{PH} v s . \mathrm{SD}$ & $0.57 * *$ & 0.14 & $0.39 * *$ & $0.25^{*}$ & $0.48 * *$ & $0.38 * *$ & 0.90 \\
\hline PH vs. GSWR & $0.59 * *$ & $0.35 * *$ & $0.65 * *$ & $0.53 * *$ & $0.73 * *$ & $0.59 * *$ & 1.00 \\
\hline PH vs. GCCR & $-0.57 * *$ & $-0.31 *$ & $-0.68 * *$ & $-0.54 * *$ & $-0.67 * *$ & $-0.61 * *$ & 1.50 \\
\hline PH vs. GLWR & 0.03 & 0.04 & 0.16 & 0.12 & -0.13 & 0.19 & 1.20 \\
\hline $\mathrm{PH} v s . \mathrm{SY}$ & $0.47 * *$ & $0.26^{*}$ & $0.58 * *$ & $0.37 * *$ & $0.78 * *$ & $0.54 * *$ & 0.90 \\
\hline SD vs. GSWR & $0.35 * *$ & 0.15 & $0.51 * *$ & $0.28 *$ & $0.32 * *$ & $0.51 * *$ & 1.00 \\
\hline SD vs. GCCR & -0.38 & -0.05 & $-0.49 * *$ & -0.18 & $-0.36 * *$ & $-0.44 * *$ & 1.40 \\
\hline SD vs. GLWR & 0.10 & -0.16 & 0.03 & $-0.27^{*}$ & 0.08 & -0.09 & 1.00 \\
\hline SD vs. SY & $0.66 * *$ & $0.63 * *$ & $0.76^{* *}$ & $0.75^{* *}$ & $0.68 * *$ & $0.78 * *$ & 1.10 \\
\hline GSWR vs. GCCR & $-0.91 * *$ & $-0.86 * *$ & $-0.92 * *$ & $-0.95 * *$ & $-0.90 * *$ & $-0.95 * *$ & 1.30 \\
\hline GSWR vs. GLWR & -0.12 & 0.03 & -0.07 & -0.02 & $-0.24 *$ & 0.06 & 1.30 \\
\hline GSWR vs. SY & $0.34 * *$ & 0.16 & $0.69 * *$ & 0.19 & $0.53 * *$ & $0.46^{* *}$ & 0.80 \\
\hline GCCR vs. GLWR & $-0.30 *$ & $-0.53 * *$ & $-0.32 * *$ & $-0.30^{*}$ & -0.22 & $-0.36^{* *}$ & 0.80 \\
\hline GCCR vs. SY & $-0.29 *$ & 0.06 & $-0.54 * *$ & -0.04 & $-0.42 * *$ & $-0.41 * *$ & 1.40 \\
\hline GLWR vs. SY & -0.09 & $-0.40 * *$ & $-0.30 *$ & $-0.45 * *$ & $-0.24 *$ & -0.07 & 0.50 \\
\hline
\end{tabular}

*; **Significant at the 0.05 and 0.01 probability levels, respectively.

PH (cm): Plant height; SD (mm): stem diameter; GSWR: green stem weight ratio (\%); GCCR: green corn cob ratio (\%); GLWR (\%): green leaf weight ratio; $\mathrm{SY}\left(\mathrm{t} \mathrm{ha}^{-1}\right)$ : silage yield. VL: Vector length of each association in Figure 4. 
experiments, correlation coefficients for investigated traits should separately be calculated for each experiment and assessed through two-way tables (Yan et al., 2007). Correlations table contains the information about the similarities and dissimilarities among test locations in terms of trait association patterns. Since the table is large and the relationships in it are complex, a biplot approach is needed to help the researcher to grasp the main patterns. The biplot that displays this type of data is called the association by environment biplot or ABE biplot (Yan, 2014).

This perspective was first recommended by Yan et al. (2007). In the present study, data set created by using the correlation coefficients between some plant characteristics and silage yield of maize genotypes was visually assessed. The biplot method allowed easy and better assessment of correlations between the traits in each environment.

\section{CONCLUSIONS}

It was observed in present study investigating different plant characteristics of maize genotypes in different environments that stem diameter, green leaf weight ratio and plant height were identified as the mostly correlated traits with silage yield in all environments.

GGE biplot method allowed efficient and reliable assessment of investigated traits in different environments. With this method, how a trait changed in each environment was identified, how traits are correlated with each other in each environment was assessed and the environments contributing the assessment of maize genotypes were identified.

It was also concluded that GGE biplot method could reliably be used in assessment of different characteristics of silage maize genotypes grown in different environments.

\section{REFERENCES}

Akcura, M. 2009. Genetic variability and interrelationship among grain yield and some quality traits in Turkish winter durum wheat landraces. Turkish Journal of Agriculture and Forestry 33:547-556.

Akcura, M. 2011. The relationships of some traits in Turkish winter bread wheat landraces. Turkish Journal Agriculture 35(2):115-125.

Akcura, M., and Kokten, K. 2017. Variations in grain mineral concentrations of Turkish wheat landraces germplasm. Quality Assurance and Safety of Crops \& Foods 9(2):153-159.

Akcura, M., Taner, S., and Kaya, Y. 2011. Evaluation of bread wheat genotypes under irrigated multi-environment conditions using GGE biplot analysis. Agriculture 98:35-40.

De Leon, N., Jannink, J.L., Edwards, J.W., and Kaeppler, S.M. 2016. Introduction to a special issue on genotype by environment interaction. Crop Science 56(5):2081-2089.

Dehghani, H., Dvorak, J., and Sabaghnia, N. 2012. Biplot analysis of salinity related traits in beard wheat (Triticum aestivum L.) Annals Biological Research 3:3723-3731.

Dehghani, H., Sabaghnia, N., and Moghaddam, M. 2009. Interpretation of genotype-by-environment interaction for late maize hybrids' grain yield using a biplot method. Turkish Journal of Agriculture and Forestry 33:139-148.
Erdal, S., Pamukcu, M., Ekiz, H., Soysal, M., Savur, O., and Toros, A. 2009. The determination of yield and quality traits of some candidate silage maize hybrids. Mediterranean Agricultural Sciences 22(1):75-81.

Gholizadeh, A., and Dehghani, H. 2016. Graphic analysis of trait relations of Iranian bread wheat germplasm under nonsaline and saline conditions using the biplot method. Genetika 48(2):473-486.

Kaplan, M., Baran, Ö., Ünlükara, A., Kale, H., Arslan, M., Kara, K., et al. 2016. The effects of different nitrogen doses and irrigation levels on yield, nutritive value, fermentation and gas production of corn silage. Turkish Journal of Field Crops 2(1):100-108.

Kusvuran, A., Kaplan, M., Nazli, R.I., Saruhan, V., and Karadag, Y. 2015. Determination of possibilities to grow some corn (Zea mays L.) cultivars for silage production under Middle Kizilirmak Basin ecological conditions. Journal of Agricultural Faculty of Gaziosmanpasa University 32(1):57-67.

Meng, Y., Ren, P., Ma, X., Li, B., Bao, Q., Zhang, H., et al. 2016. GGE biplot-based evaluation of yield performance of barley genotypes across different environments in China. Journal of Agricultural Science and Technology 18(2):533-543.

Mohammadi, R., and Amri, A. 2016. Genotype $\times$ Environment interaction implication: A case study of durum wheat breeding in Iran. Chapter 14. p. 515-558. In Al-Khayri, J.M., Jain, S.M., and Johnson, D.V. (eds.) Advances in plant breeding strategies: Agronomic, abiotic and biotic stress traits. Springer, Cham, Switzerland.

Mohammadi, R., Amri, A., and Ansari, Y. 2009. Biplot analysis of rainfed barley multienvironment trials in Iran. Agronomy Journal 101(4):789-796.

Rahmatollah, K., Mohtasham, M., Naser, S., Ali, A.M., Barzo, R., Faramarz, S.M., et al. 2013. GGE Biplot analysis of yield stability in multienvironment trials of lentil genotypes under rainfed condition. Notulae Science Biologicae 5(2):256-262.

Roozeboom, K.L., Schapaugh, W.T., Tuinstra, M.R., Vanderlip, R.L., and Milliken, G.A. 2008. Testing wheat in variable environments: genotype, environment, interaction effects, and grouping test locations. Crop Science 48(1):317-330.

SAS Institute. 1999. SAS/STAT user's guide, Vers. 8. SAS Institute, Cary, North Carolina, USA.

Villegas, H.V., Wright, E.M., and Kelly, J.D. 2016. GGE Biplot analysis of yield associations with root traits in a Mesoamerican bean diversity panel. Crop Science 56(3):1081-1094.

Yan, W. 2014. Crop variety trials: Data management and analysis. 349 p. Wiley-Blackwell, Hoboken, New Jersey, USA.

Yan, W., and Frégeau-Reid, J. 2008. Breeding line selection based on multiple traits. Crop Science 48:417-423.

Yan, W., Frégeau-Reid, J., Pageau, D., Martin, R., Mitchell-Fetch, J., Etienne, M., et al. 2010. Identifying essential test locations for oat breeding in eastern Canada. Crop Science 50(2):504-515.

Yan, W., and Tinker, N.A. 2005. An integrated biplot analysis system for displaying, interpreting, and exploring genotype-byenvironment interactions. Crop Science 45:1004-1016.

Yan, W., Tinker, N.A., Molnar, S., Fregeau-Reid, J., and McElroy, A. 2007. Associations among oat traits and their responses to the environment in North America. Journal of Crop Improvement 20:1-29. 